Research Article

\title{
Estimating the Compressive Strength of Cement-Based Materials with Mining Waste Using Support Vector Machine, Decision Tree, and Random Forest Models
}

\author{
Hongxia Ma, ${ }^{1}$ Jiandong Liu, ${ }^{2}$ Jia Zhang, ${ }^{2}$ and Jiandong Huang $\mathbb{D}^{2}$ \\ ${ }^{1}$ Jiangsu Province Xuzhou Technician Institute, Xuzhou 221116, China \\ ${ }^{2}$ School of Mines, China University of Mining and Technology, Xuzhou 221116, China \\ Correspondence should be addressed to Jiandong Huang; huang@cumt.edu.cn
}

Received 29 October 2020; Accepted 2 August 2021; Published 7 August 2021

Academic Editor: Junfei Zhang

Copyright (c) 2021 Hongxia Ma et al. This is an open access article distributed under the Creative Commons Attribution License, which permits unrestricted use, distribution, and reproduction in any medium, provided the original work is properly cited.

To estimate the compressive strength of cement-based materials with mining waste, the dataset based on a series of experimental studies was constructed. The support vector machine (SVM), decision tree (DT), and random forest (RF) models were developed and compared. The beetle antennae search (BAS) algorithm was employed to tune the hyperparameters of the developed machine learning models. The predictive performances of the three models were compared by the evaluation of the values of correlation coefficient $(R)$ and root mean square error (RMSE). The results showed that the BAS algorithm can effectively tune these artificial intelligence models. The SVM model can obtain the minimum RMSE, while the BAS algorithm is inefficient in DT and RF models. The SVM, DT, and RF models can be used to predict the compressive strength of cement-based materials using solid mining waste as aggregate effectively and accurately, with high $R$ values and lower RMSE values. The RF algorithm can obtain the highest value of $R$ and the lowest value of RMSE, demonstrating the highest accuracy. The solid mining waste to cement ratio is the most important variable to affect the compressive strength. Curing time was also an important parameter in the compressive strength of cemented materials, followed by the water-solid ratio of mining waste and fine sand ratio.

\section{Introduction}

The mining waste includes the stripping and waste rock (including coal gangue) produced in the process of mining, as well as the tailings discarded in the process of mineral dressing [1-6]. A large amount of mining solid waste as well as the complicated treatment has become one of the issues that should be addressed for environmental protection [4, 7-12]. The massive accumulation of mining waste can cause pollution of the land, causing disasters such as landslides and mudslides. The debris and tailings formed by the weathering of waste rock are either washed by water into the water body, dissolved and penetrated into the groundwater, or blown into the atmosphere by the wind, polluting the environment with water and gas as the medium [13-16]. These mining waste materials not only take up a lot of land but also directly pollute the environment and threaten the safety of people's lives, since some of these wastes contain highly toxic elements, such as arsenic and cadmium, and radioactive elements, which are harmful to human health $[1,2,4,7-9]$. Tailings have the characteristics of fine particles, small weight, large surface area, being easy to run away in contact with water, and being easy to fly when exposed to wind. Therefore, those solid mining wastes are a potential hazard to the air, water bodies, farmland, and villages $[4,13,17-20]$.

To address such issue of solid mining waste, researchers have started various approaches to recycling and reproduction of those construction materials using the mining waste, and one of the most representative cases is the widely used cement-based materials which can be produced environmentally friendly if the main aggregates can be replaced by the mining waste [21-31]. In general, cement and water should be added to cement-based composites to increase 
strength and fluidity. After mixing with water, the slurry can be hardened in the water, and the sand, stone, and other materials can be firmly cemented together [32-40]. Due to its important role as a building material, it has received more and more attention in recent years, especially in the research objectives of strength and durability [41-49].

As mentioned above, compressive strength is a key index for evaluating the construction process and workability of cement-based composites, so most studies focus on experiments and revealing mechanisms [50-57]. Typically, the strength of cement-based materials is tested in the laboratory and the practical civil engineer finds the optimized proportion of the constituent materials in the composition [58-66]. However, experimental research is time-consuming and expensive and is not suitable for a large number of laboratory tests [41, 42, 67-72]. Some researchers have applied empirical formulas to predict the strength of cement-based materials using the so-called mathematical regression, in which some of the empirical formulas are useful, but most of them are limited by the input and output dataset. Because of the low accuracy of the empirical formula, its scope of application has barely been realized. Hence, to accurately predict the compressive strength of cement-based materials, simpler and more reliable models should be proposed.

Using artificial intelligence methods to evaluate and predict the mechanical properties of cement-based materials is a hot spot in the research field of cement-based composites $[35,39,63]$. Besides, some researchers have applied machine learning methods to evaluate the performance of cementbased composites. For example, artificial neural networks (ANN) and other evolutionary optimization algorithms have been used to predict the compressive strength of cementbased materials. Jamal et al. analyzed the potential to use multiple linear regression and adaptive neurofuzzy reasoning systems for the estimation of the strength of recycled aggregate concrete [73]. Khademi and Jamal used the same method in a follow-up study to predict the compressive strength of the recycled aggregate concrete after curing for 28 days [74]. The measured results of the above-mentioned method were consistent with the predicted ones, indicating that the machine learning techniques are feasible for the performance prediction of the cemented-based materials. However, limited studies can support accurate and efficient artificial intelligence techniques that specifically target the compressive strength of the cemented-based materials that use the mining waste as the aggregates. Also, it should be noted that the above machine learning techniques have been successfully adapted to the prediction of the concrete materials, but these studies still have the limitations of uncertainty, being time-consuming, and low efficiency. Therefore, it is necessary to propose more efficient and simple machine learning techniques to evaluate the compressive strength of the cemented-based materials that use the mining waste as the aggregates. Besides, more intelligent algorithms such as random forest, support vector machine, and decision tree are also applied in this field. It should be noted that most machine learning models can make predictions accurately, but there is limited research on the impact of different models on the accuracy of predictions. The above algorithms have different sensitivities to datasets with different attributes. Therefore, it is necessary to use different models for predictive compression and to find the optimal model for future applications.

In this study, various experimental tests were conducted to construct the dataset considering four key factors, that is, solid mining waste to cement ratio, fine sand ratio, solid mining waste to water ratio, and curing time. Then three machine learning models, that is, SVM, DT, and RF, were used for the prediction of the strength of cement-based materials using the mining waste as the aggregates, and the hyperparameters of these models were tuned by beetle antennae search (BAS) algorithm. Last, the prediction results were compared and analyzed, which give the best models in compressive strength prediction of the cement-based materials. Also, the importance of influencing variables was conducted and the most sensitive factor was found. The study provides the best models for strength prediction of cement-based materials, which is an important guideline in this research field.

\section{Methodology}

2.1. Dataset Collection. In the present study, the compressive strength dataset used for the prediction of cement-based materials was collected from the previous studies by the authors. The tailings were employed as the solid mining waste for the replacement of the aggregates. Four parameters confirmed to be the influenced variables for the compressive strength of the cement-based materials were determined as the input: the ratio of the solid mining waste to the cement, fine sand ratio, the ratio of the solid mining waste to water, and the curing time. Table 1 presents the composition of the dataset.

The solid mining waste to the cement ratio was determined as $4,6,8$, and 10 , respectively. The fine sand ratio concerning the total mixture was selected as $0,0.1,0.15$, and 0.2 . The solid mining waste to water ratio was determined as $0.68,0.7$, and 0.72 , respectively. The concrete samples were cured for 7, 28, and 60 days. Table 2 shows the statistical analysis of these variables in the dataset.

The Pearson correlation coefficient was employed in this study to evaluate the relationship between the input parameters. The Pearson correlation coefficient between two input variables is defined as the quotient of covariance and standard deviation between two variables, as shown in the following equation:

$$
\rho_{X Y}=\frac{\operatorname{cov}(X, Y)}{\sigma_{X} \sigma_{Y}}=\frac{E\left[\left(X-\mu_{X}\right)\left(Y-\mu_{Y}\right)\right]}{\sigma_{X} \sigma_{Y}} .
$$

Correspondingly, the correlation of the collected dataset was analyzed by SPSS software in the present study. Figure 1 gives the correlation matrix between the input variables (the solid mining waste to cement ratio, fine sand ratio, solid mining waste to water ratio, and curing time).

It can be found from Figure 1 that the correlation between the two same variables is 1 on the diagonal from the bottom left 
TABle 1: Composition of the dataset.

\begin{tabular}{lccc}
\hline Solid mining waste to cement ratio & Fine sand ratio & Solid mining waste to water ratio & Curing time \\
\hline $4,6,8$, and 10 & $0,0.1,0.15,0.2$ & $0.68,0.70,0.72$ & $7,28,60$ days \\
\hline
\end{tabular}

TABLE 2: Statistical analysis of these variables in the dataset.

\begin{tabular}{|c|c|c|c|}
\hline Dataset & Variables & Mean & Std \\
\hline \multirow{4}{*}{ Training dataset (the number of data points is 100 ) } & Solid mining waste to cement ratio (\%) & 70.14 & 1.61 \\
\hline & Fine sand ratio $(\%)$ & 11.15 & 7.24 \\
\hline & Solid mining waste to water ratio (\%) & 6.92 & 2.16 \\
\hline & Curing time $(\mathrm{d})$ & 33.53 & 21.14 \\
\hline \multirow{4}{*}{ Testing dataset (the number of data points is 44 ) } & Solid mining waste to cement ratio & 69.68 & 1.65 \\
\hline & Fine sand ratio & 11.48 & 7.73 \\
\hline & Solid mining waste to water ratio & 7.18 & 2.39 \\
\hline & Curing time & 27.43 & 22.64 \\
\hline
\end{tabular}

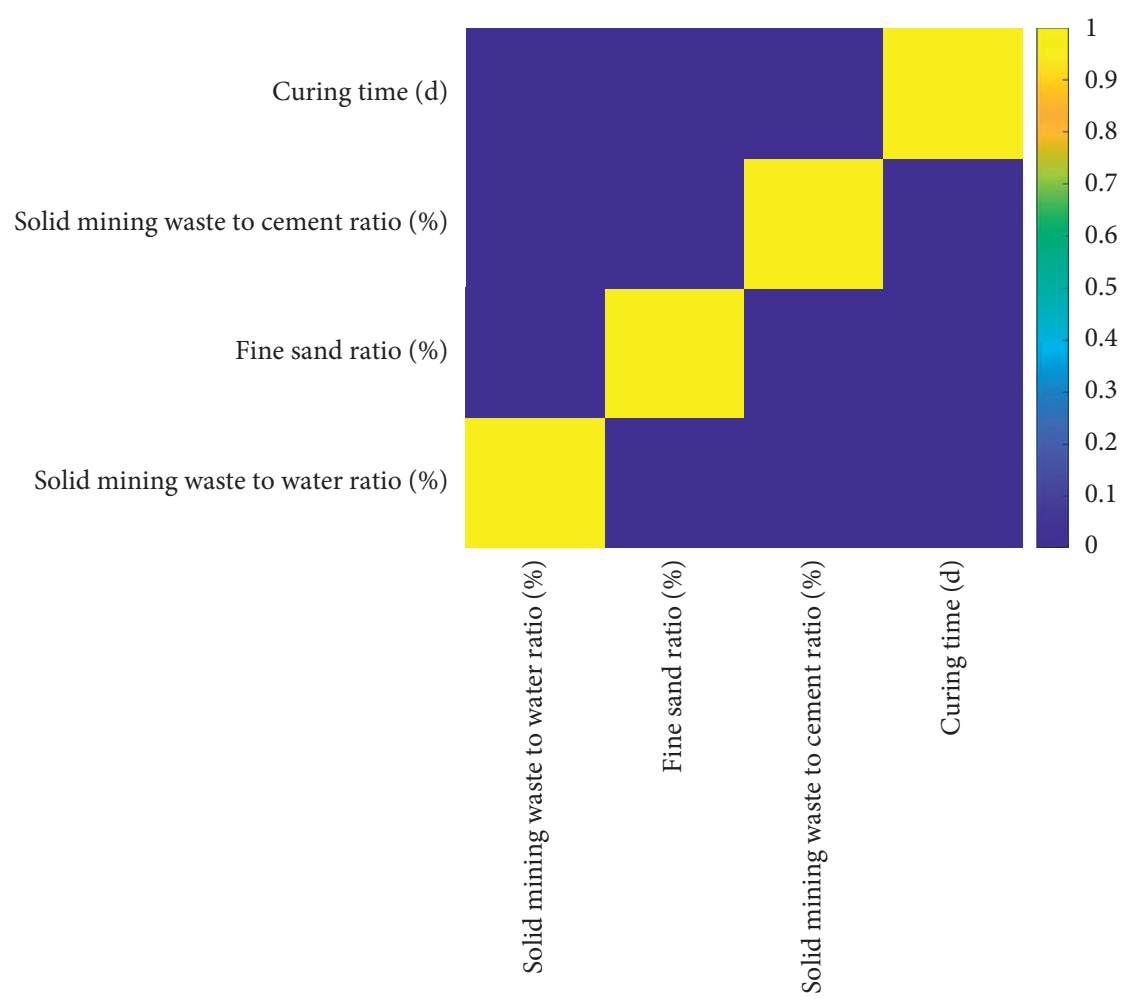

Figure 1: Correlation matrix of the input matrix.

to the top right and the correlation coefficient of the part above the diagonal is symmetric with the correlation coefficient of the part below the diagonal. The correlation coefficients between the different variables are relatively low (most values are close to 0.1 ). This indicates that these input variables are independent of each other, so they can be used as input variables for intelligent prediction of compressive strength of the concrete samples without causing multicollinearity issues.

2.2. Artificial Intelligence Algorithms. In the present study, three artificial intelligence algorithms, SVM, DT, and RF, were employed to predict the compressive strength of concrete samples with tailings as aggregate.
Support vector regression (SVR) seeks an estimation indicator function, which can be used to classify test samples [60]. By extending the problem from seeking indication function estimation to seeking real-valued function estimation, a support vector machine (SVM) for function estimation (regression) can be obtained [75-77]. SVM effectively solves the problems of a small number of samples, high dimension, and nonlinearity [78, 79]. However, as a new machine learning algorithm, there are still some areas to be improved, and the selection of its parameters (including error $\varepsilon$, error penalty factor $C$, and kernel function parameters $y$ ) is one of the problems to be improved $[60,80,81]$. The kernel function parameter $Y$ affects the complexity of the distribution of sample data in the high- 
dimensional feature space. The change of kernel parameters implicitly changes the mapping function, thus changing the dimension of the sample space. For an indicator function set, if there are $H$ samples that can be separated by all possible forms of two to $H$ of the function set, then the function set is said to be able to shatter $H$ samples. The Vapnik-Chervonenkis (VC) dimension of a set of functions is the maximum number of samples it can shatter. If there are functions that can shatter any number of samples, then the $\mathrm{VC}$ dimension of the set of functions is infinite, and the VC dimension of a bounded real function can be defined by converting it to an indicator function with a certain threshold.

The DT model is a decision analysis method that obtains the probability that the expected value of net present value is greater than or equal to zero, evaluates the project risk, and judges its feasibility based on the known probability of occurrence of various situations by forming a decision tree. The DT model is a graphical method that directly uses probability analysis. In machine learning, the DT algorithm can be used as a prediction model, which represents a mapping relationship between object attributes and object values.

$\mathrm{RF}$ is an algorithm that integrates multiple trees through the idea of ensemble learning. Its basic unit is the decision tree, and its essence belongs to the ensemble learning method of machine learning. In fact, from an intuitive point of view, each decision tree is a classifier. Therefore, for input with $n$ samples, $n$ trees will have $n$ classification results. The $\mathrm{RF}$ algorithm integrates all the classification voting results and designates the category with the most votes as the final output. In the RF algorithm, $k$ feature columns are randomly selected from the dataset with a total of $m$ features (where $k$ is less than or equal to $m$ ), and then a decision tree is established based on these $k$ features. This process should be repeated $n$ times, and $n$ decision trees can be built from the $k$ properties through different random combinations. Finally, the random variables are passed to each decision tree to predict the outcome.

In this study, the input variables of the model are the ratio of solid waste to cement, the ratio of fine sand, the ratio of solid waste to water, and the curing time, and the output is the compressive strength of concrete samples. These machine learning algorithms are widely used to address the regression problems in the engineering area such as the prediction of the concrete performance, rock performance, and rockburst. However, these models have not been compared to find the optimized one, especially regarding the concrete samples with tailings as aggregate. Therefore, it is necessary to compare them and find out the best model to predict the compressive strength of concrete specimens with mining waste as aggregate.

2.3. Evaluation of the Predictive Performance. The evaluation method is crucial for the performance of machine learning models because it can help researchers find the optimal algorithm for application. In this study, the dataset is divided into two parts: the training set $(70 \%$, including 100 data points) and the testing set (30\%, including 44 data points).
Each dataset was then validated using a 10 -fold cross-validation method. According to the literature, the correlation coefficient $(R)$ and root mean square error (RMSE) were used in this study to evaluate the performance of the applied model. The two parameters can be described as follows:

$$
\begin{aligned}
R & =\frac{\sum_{i=1}^{N}\left(y_{i}^{*}-\overline{y^{*}}\right)\left(y_{i}-\bar{y}\right)}{\sqrt{\sum_{i=1}^{N}\left(y_{i}^{*}-\overline{y^{*}}\right)^{2}} \sqrt{\sum_{i=1}^{N}\left(y^{i}-\bar{y}\right)^{2}}}, \\
\text { RMSE } & =\sqrt{\frac{1}{N} \sum_{i=1}^{N}\left(y_{i}^{*}-y_{i}\right)^{2}},
\end{aligned}
$$

where $N$ represents the number of datum, which is 144 in the present study; $y * i$ and $y_{i}$ represent the expected and measured compressive strengths of the concrete samples, respectively; $\bar{y}$ and $\overline{y^{*}}$ are the average values of the predicted and measured compressive strengths of the concrete samples, respectively.

\section{Results and Discussion}

3.1. Experimental Results of the Compressive Strength. Figure 2 gives the experimental results of the compressive strength of the concrete samples using the tailings as the aggregate and all the datasets, the solid mining waste to cement ratio, fine sand ratio, solid mining waste to water ratio, and curing time, are summarized in it.

As can be seen from Figure 2, the influence of fine sand ratio on the compressive strength of concrete specimens is generally negative, that is, with the decrease of fine tailings, the compressive strength of concrete specimens increases. However, it should be noted that, in some cases, the effect of fine tailings is not clear. In addition, with the increase of curing time, the compressive strength of concrete specimens increases rapidly. The solid mining waste to water ratio also has a similar influencing effect, and the compressive strength of concrete samples increases with the increase of the solid mining waste to water ratio. However, with the increase of solid mining waste to cement ratio, its strength decreases. The experimental results are consistent with the results of the previous literature, indicating that the dataset is reliable and accurate.

\subsection{Hyperparameters Tuning. Figure 3 gives the relationship} between iterations and RMSE values.

For different artificial intelligence algorithms, BAS is used to find the optimized hyperparameters. As can be seen from Figure 3, RMSE drops rapidly after several iterations and then remains stable, indicating that BAS can effectively tune these artificial intelligence models. The reduction rates of RMSE values of the three models are similar, indicating the lower difference in computational efficiency. Also, it can be clearly seen from Figure 3 that, due to the hyperparameters tuning of the BAS algorithm, the SVM model can obtain the minimum RMSE, while BAS algorithm is inefficient in DT and RF models. In summary, the BAS algorithm is efficient and accurate in the hyperparameter tuning 


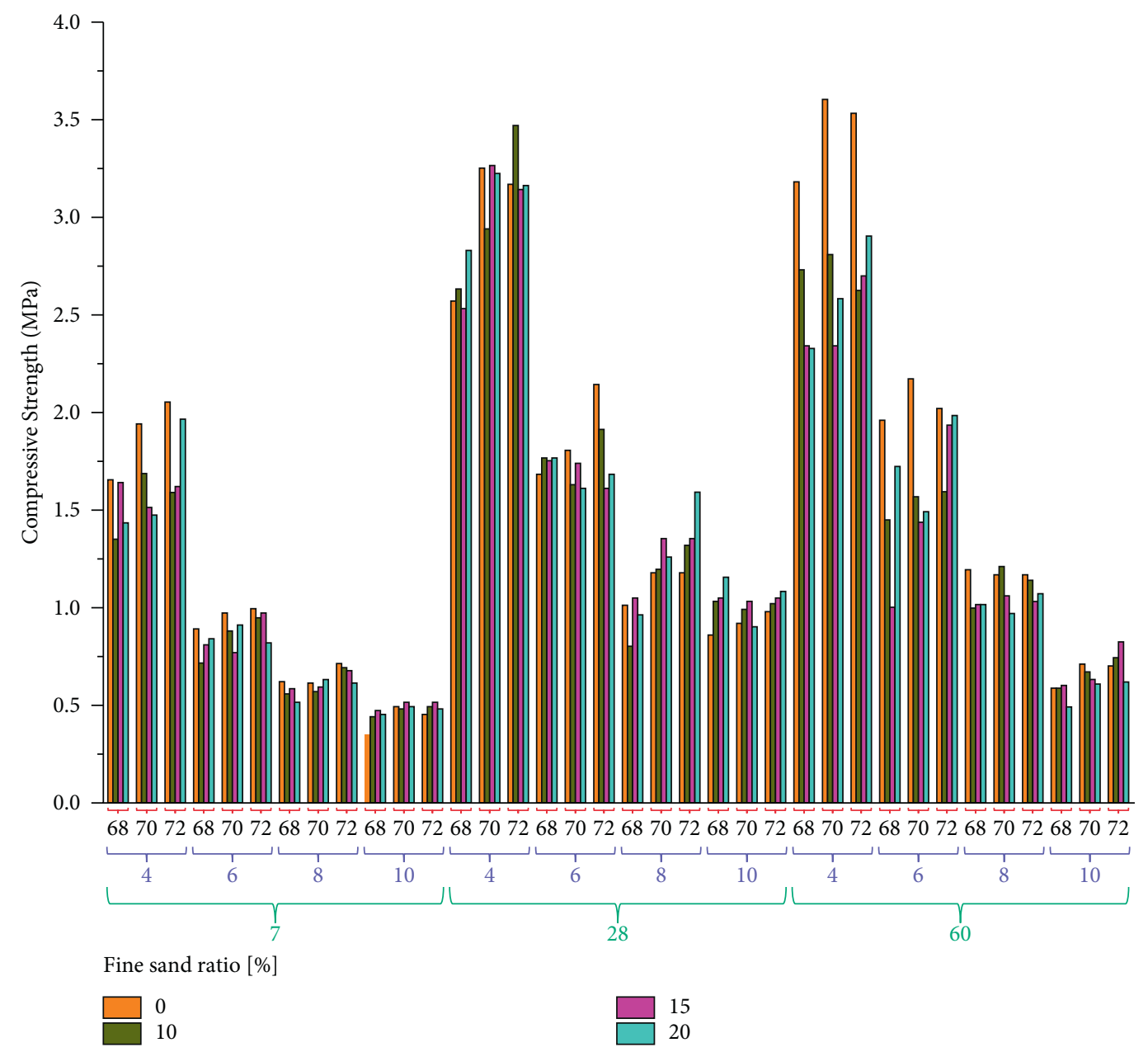

FIgURE 2: Experimental results.

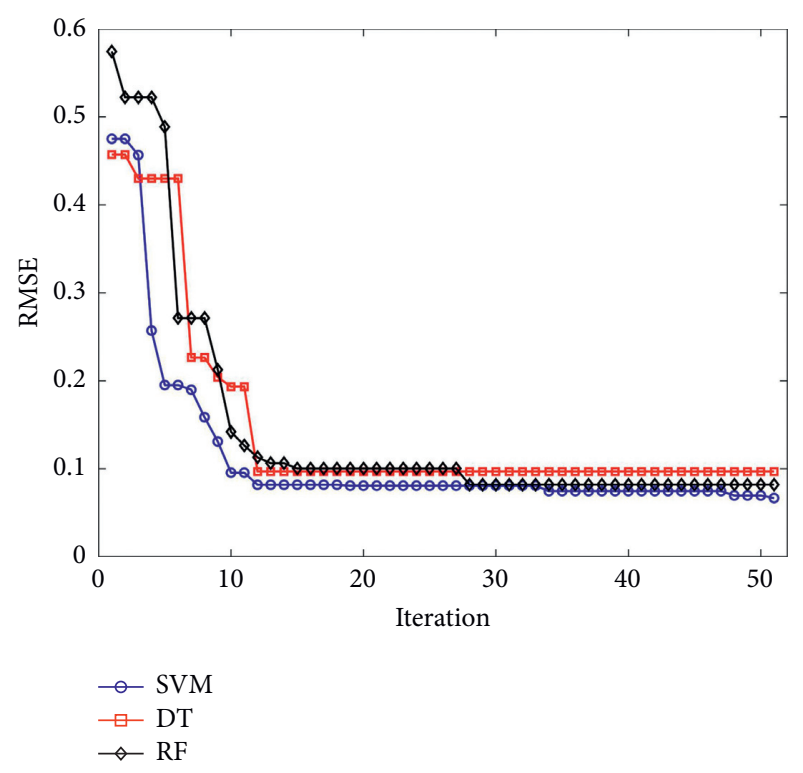

FIGURE 3: Relationship between the iterations and RMSE values for different models. process of the three models and the following model evaluation process can be conducted.

The 10-fold cross-validation (CV) was employed for the hyperparameter tuning in the three machine learning models. Figures 4-6 give the RMSE values of different folds using the SVM, DT, and RF models, respectively.

It can be seen from the figures that the SVM model can obtain the minimum value of RMSE at the 4th fold with a value of 0.065 during the 10 -fold $C V$ process. The minimum value of RMSE in the DT model can be obtained at the 4th fold as well, with a value of 0.095 . RF model can obtain the minimum value of RMSE at the 7th fold with a value of 0.08 .

3.3. Model Evaluation. The predictive results of the three machine learning models employed in this study were systematically compared. Figures 7-9 give the results of the comparison between the actual compressive strength and predicted compressive strength using the SVM model, DT model, and RF model, respectively.

It can be observed that the RMSE values (test set) of the SVM model, DT model, and RF model were $0.2332,0.24$, and 


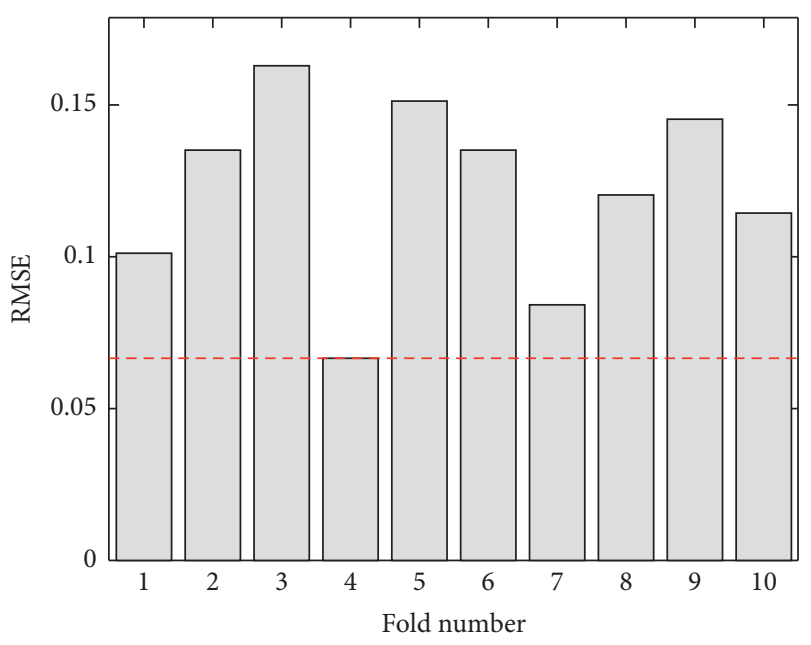

FIGURE 4: RMSE values of different folds (SVM model).

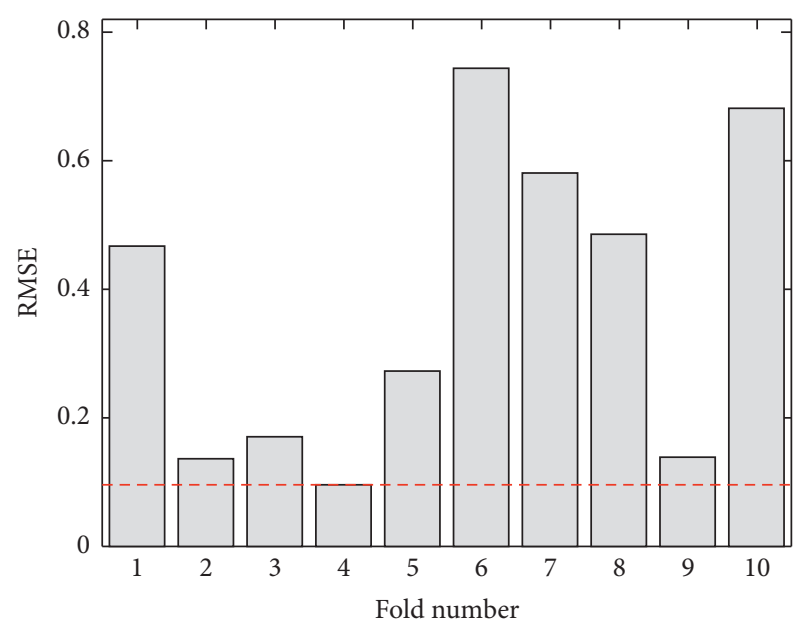

Figure 5: RMSE values of different folds (DT model).

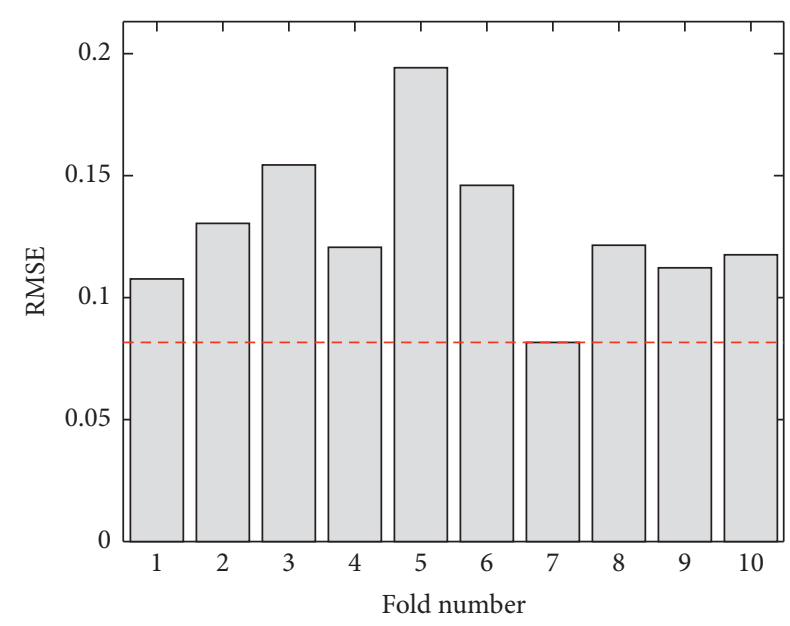

FIGURE 6: RMSE values of different folds (RF model).

0.2286, respectively. $R$ values (test set) of the SVM model, DT model, and RF model were 0.9699, 0.9619, and 0.9731, respectively. It is indicated that the RF model is the

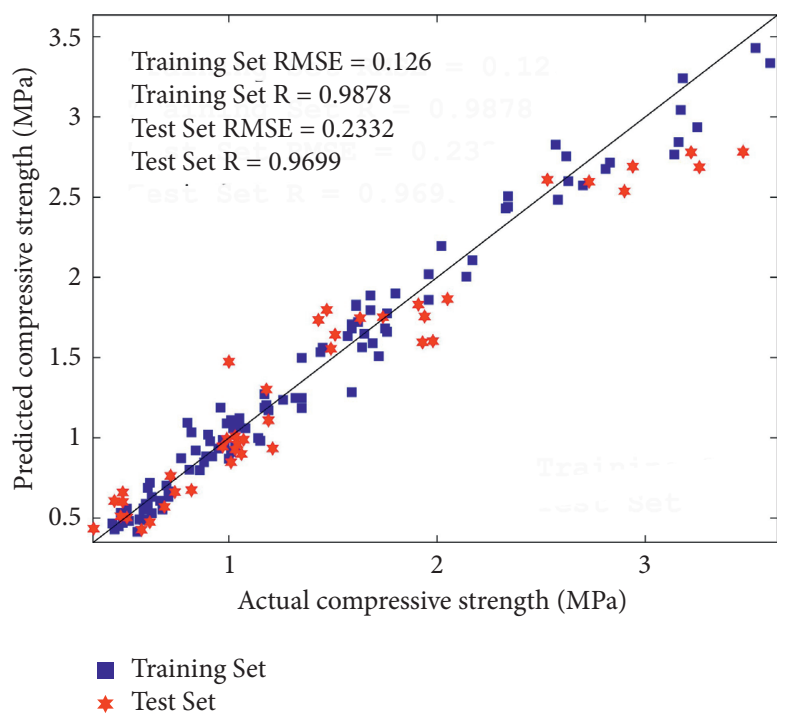

FIgURE 7: Comparison of the actual compressive strength and predicted compressive strength (SVM model).

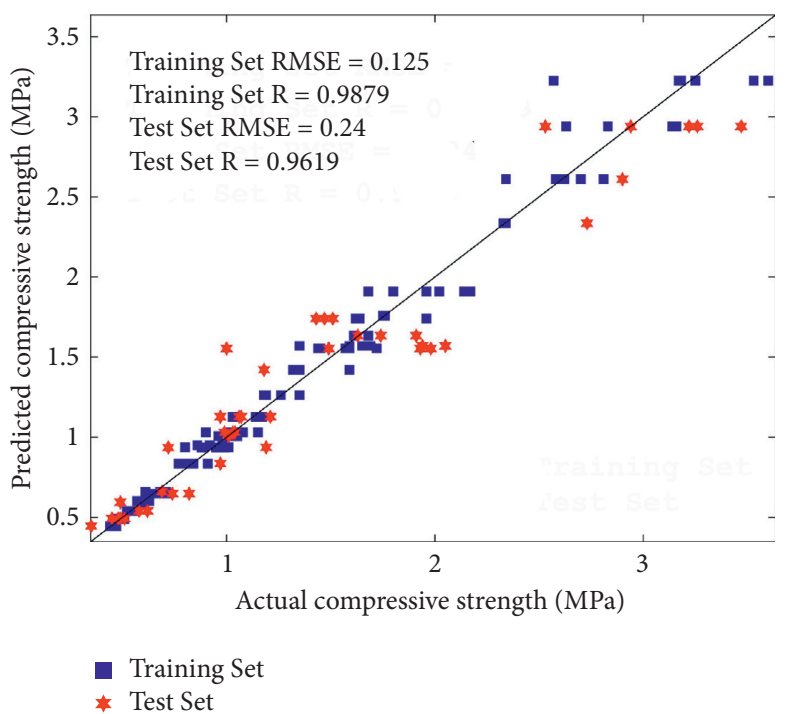

FIgURE 8: Comparison of the actual compressive strength and predicted compressive strength (DT model).

optimized machine learning algorithm to predict the compressive strength of the cement-based materials using the tailings as the aggregates. However, it should be noted that the predictive performances of the three models are quite similar (less than 5\%).

3.4. Variable Importance Evaluation. The model can effectively predict the compressive strength of the cementing material of tailings as aggregate, and the relative importance of each variable can be determined by the machine learning model. To achieve optimal prediction performance, the RF model was used to calculate the importance of variables in this study, and the results are shown in Figure 10. 


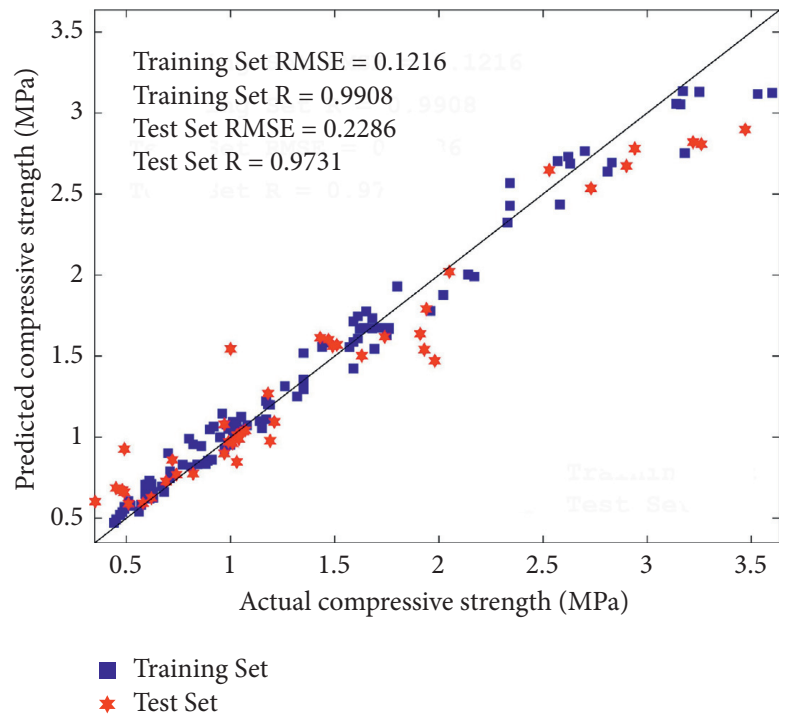

FIGURE 9: Comparison of the actual compressive strength and predicted compressive strength (RF model).

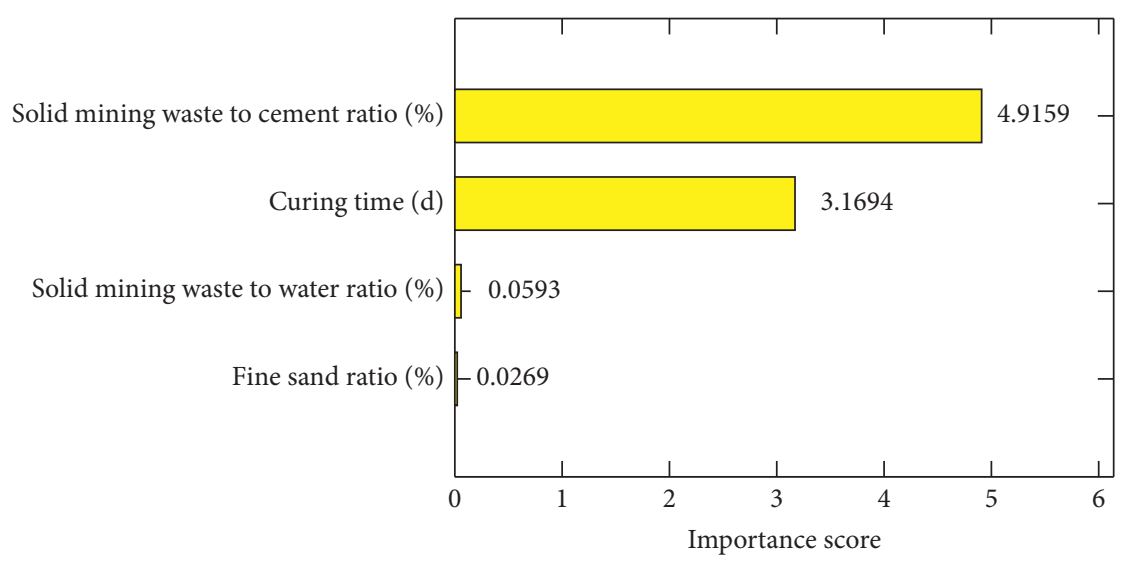

FIGURE 10: Importances of different variables.

It can be seen that the solid mining waste to cement ratio is the most important variable, and its influence score is 4.9159. Curing time (3.1694) can also be used as an important parameter in the compressive strength of cemented materials relative to the total amount of mining waste, followed by the water-solid ratio of mining waste (0.0593) and fine sand ratio (0.0269), indicating that engineers should pay more attention to the ratio of solid mining waste to cement. The above results have a certain guiding significance for the mix design of the cemented materials with mining waste as aggregate and field construction.

\section{Conclusions}

Based on a series of experimental studies on cement-based materials with mining waste as the aggregates, the dataset was constructed and the model was evaluated. Three machine learning models (SVM, DT, and RF) were used to predict the compressive strength of cement-based materials with mining waste as the aggregates, and the prediction results of different models were compared. The corresponding results are as follows:

(1) The results of compressive strength of cement-based materials show that, with the increase of water content and curing time of solid mine waste, the compressive strength of cement-based materials increases, while it decreases with the increase of fine sand ratio and solid waste rock cement ratio.

(2) The BAS algorithm can effectively tune these artificial intelligence models. The reduction rates of RMSE values of the three models are similar, indicating the lower difference in computational efficiency. Due to the hyperparameters tuning of the BAS algorithm, the SVM model can obtain the minimum RMSE, while the BAS algorithm is inefficient in DT and RF models.

(3) Based on the prediction results from the developed model, the SVM, DT, and RF models can be used to 
predict the compressive strength of cement-based materials using solid mining waste as aggregate effectively and accurately, with high $R$ values $(0.9699,0.9619$, and 0.9731 for the SVM, DT, and RF models) and lower RMSE values (SVM, DT, and RF models were $0.2332,0.24,0.2286$, respectively). Comparing the three developed models, the RF algorithm can obtain the highest value of $R$ and the lowest value of RMSE, demonstrating the highest accuracy.

(4) The solid mining waste to cement ratio is the most important variable to affect the compressive strength of the cement-based materials using the mining waste as the aggregates. Curing time was also an important parameter in the compressive strength of cemented materials relative to the total amount of mining waste, followed by the water-solid ratio of mining waste and fine sand ratio. These results have a certain guiding significance for the mix design of the cemented materials with mining waste as aggregate and field construction in the future.

It should be pointed out that the accuracy and reliability of these developed machine learning models depend on the dataset, that is, the number and type of samples. Therefore, in the future, more samples will need to be obtained and more efficient models should be proposed.

\section{Data Availability}

The data used to support the findings of this study are available from the corresponding author upon request.

\section{Conflicts of Interest}

There are no conflicts of interest.

\section{References}

[1] X. Zhang, Q. Jiang, N. Chen, W. Wei, and X. Feng, "Laboratory investigation on shear behavior of rock joints and a new peak shear strength criterion," Rock Mechanics and Rock Engineering, vol. 49, no. 9, pp. 3495-3512, 2016.

[2] G. You, M. A. Mandalawi, A. Soliman, K. Dowling, and P. Dahlhaus, "Finite element analysis of rock slope stability using shear strength reduction method," in Proceedings of the International Congress and Exhibition "Sustainable Civil Infrastructures: Innovative Infrastructure Geotechnology, pp. 227-235, Springer, Sharm El Sheikh, Egypt, July 2017.

[3] C. Xu, M. N. Amar, M. A. Ghriga, H. Ouaer, X. Zhang, and M. Hasanipanah, "Evolving support vector regression using grey wolf optimization; forecasting the geomechanical properties of rock," Engineering with Computers, pp. 1-15, 2020.

[4] H. Xie, J.-A. Wang, and W.-H. Xie, "Fractal effects of surface roughness on the mechanical behavior of rock joints," Chaos, Solitons \& Fractals, vol. 8, no. 2, pp. 221-252, 1997.

[5] Z. Sun, J. Shi, K. Wu, T. Zhang, D. Feng, and X. Li, "Effect of pressure-propagation behavior on production performance: implication for advancing low-permeability coalbed-methane recovery," SPE Journal, vol. 24, no. 2, pp. 681-697, 2019.
[6] Z. Sun, X. Li, W. Liu, T. Zhang, M. He, and H. Nasrabadi, "Molecular dynamics of methane flow behavior through realistic organic nanopores under geologic shale condition: pore size and kerogen types," Chemical Engineering Journal, vol. 398, Article ID 124341, 2020.

[7] R. Wu, P. Kulatilake, H. Luo, and K. Zhao, "Design of the key bearing layer and secondary mining technology for previously mined areas of small coal mines," Rock Mechanics and Rock Engineering, vol. 53, pp. 1-15, 2019.

[8] G. Tiwari and G. M. Latha, "Shear velocity-based uncertainty quantification for rock joint shear strength," Bulletin of Engineering Geology and the Environment, vol. 78, no. 8, pp. 5937-5949, 2019.

[9] D. Tarchi, G. Antonello, N. Casagli et al., "On the use of ground-based sar interferometry for slope failure early warning: the cortenova rock slide (Italy)," in Landslides, pp. 337-342, Springer, Berlin, Germany, 2005.

[10] F. Xiao, T. Wang, X. Hou, J. Yuan, C. Jiang, and Y. Luo, "Waterproof and antiscour properties of asphalt-based composite seals for airfield base layer," Journal of Materials in Civil Engineering, vol. 32, no. 1, Article ID 04019328, 2020.

[11] T. Wang, J. Wang, X. Hou, and F. Xiao, "Effects of sara fractions on low temperature properties of asphalt binders," Road Materials and Pavement Design, vol. 22, no. 3, pp. 539-556, 2021.

[12] X. Hou, F. Xiao, R. Guo, Q. Xiang, T. Wang, and J. Wang, "Application of spectrophotometry on detecting asphalt content of emulsified asphalt," Journal of Cleaner Production, vol. 215, pp. 626-633, 2019.

[13] Z. C. Tang and L. N. Y. Wong, "New criterion for evaluating the peak shear strength of rock joints under different contact states," Rock Mechanics and Rock Engineering, vol. 49, no. 4, pp. 1191-1199, 2016.

[14] D. Sow, C. Carvajal, P. Breul et al., "Modeling the spatial variability of the shear strength of discontinuities of rock masses: application to a dam rock mass," Engineering Geology, vol. 220, pp. 133-143, 2017.

[15] M. Souley, F. Homand, and B. Amadei, "An extension to the saeb and amadei constitutive model for rock joints to include cyclic loading paths," International Journal of Rock Mechanics and Mining Science \& Geomechanics Abstracts, pp. 101-109, Elsevier, 1995.

[16] K. Senthil, A. Arockiarajan, R. Palaninathan, B. Santhosh, and K. M. Usha, "Defects in composite structures: its effects and prediction methods - a comprehensive review," Composite Structures, vol. 106, pp. 139-149, 2013.

[17] R. Resende, J. Muralha, A. L. Ramos, and E. Fortunato, "Rock joint topography: three-dimensional scanning and numerical analysis," Géotechnique Letters, vol. 5, no. 4, pp. 318-323, 2015.

[18] H. Yu, Z. Zhu, Z. Leng et al., "Effect of mixing sequence on asphalt mixtures containing waste tire rubber and warm mix surfactants," Journal of Cleaner Production, vol. 246, Article ID 119008, 2020.

[19] H. Yu, Z. Leng, Z. Zhou, K. Shih, F. Xiao, and Z. Gao, "Optimization of preparation procedure of liquid warm mix additive modified asphalt rubber," Journal of Cleaner Production, vol. 141, pp. 336-345, 2017.

[20] H. Yu, G. Deng, Z. Zhang, M. Zhu, M. Gong, and M. Oeser, "Workability of rubberized asphalt from a perspective of particle effect," Transportation Research Part D: Transport and Environment, vol. 91, Article ID 102712, 2021.

[21] J. Zhao, D. Wang, P. Yan, D. Zhang, and H. Wang, "Selfcementitious property of steel slag powder blended with 
gypsum," Construction and Building Materials, vol. 113, pp. 835-842, 2016.

[22] S. Zhang, Y. Fan, J. Huang, and S. P. Shah, "Effect of nanometakaolinite clay on the performance of cement-based materials at early curing age," Construction and Building Materials, vol. 291, Article ID 123107, 2021.

[23] H. Zhang, H. Li, Y. Zhang, D. Wang, J. Harvey, and H. Wang, "Performance enhancement of porous asphalt pavement using red mud as alternative filler," Construction and Building Materials, vol. 160, pp. 707-713, 2018.

[24] S. Yin, A. Wu, K. Hu, Y. Wang, and Y. Zhang, "The effect of solid components on the rheological and mechanical properties of cemented paste backfill," Minerals Engineering, vol. 35, pp. 61-66, 2012.

[25] Y.-j. Xie, Q. Fu, K.-R. Zheng, Q. Yuan, and H. Song, “Dynamic mechanical properties of cement and asphalt mortar based on shpb test," Construction and Building Materials, vol. 70, pp. 217-225, 2014.

[26] K. Xie, Y. Du, and C. Sun, "Application of the mind-evolution-based machine learning in mixture-ratio calculation of raw materials cement," in Proceedings of the 3rd World Congress on Intelligent Control and Automation (Cat. No. OOEX393), pp. 132-134, IEEE, Hefei, China, June 2000.

[27] M. Wu, R. Li, Y. Zhang, J. Wei, Y. Lv, and X. Ding, "Reinforcement effect of fiber and deoiled asphalt on high viscosity rubber/sbs modified asphalt mortar," Petroleum Science, vol. 11, no. 3, pp. 454-459, 2014.

[28] Z. Y. Wang, G. X. Mei, and X. B. Yu, "Dynamic shear modulus and damping ratio of waste granular rubber and cement soil mixtures," Advanced Materials Research, Trans Tech Publ, vol. 243-249, pp. 2091-2094, 2011.

[29] Q.-A. Wang, J. Zhang, and J. Huang, "Simulation of the compressive strength of cemented tailing backfill through the use of firefly algorithm and random forest model," Shock and Vibration, vol. 2021, Article ID 5536998, 9 pages, 2021.

[30] H. Wang, H. Li, X. Liang, H. Zhou, N. Xie, and Z. Dai, "Investigation on the mechanical properties and environmental impacts of pervious concrete containing fly ash based on the cement-aggregate ratio," Construction and Building Materials, vol. 202, pp. 387-395, 2019.

[31] A. Torres, J. Hu, and A. Ramos, "The effect of the cementitious paste thickness on the performance of pervious concrete," Construction and Building Materials, vol. 95, pp. 850-859, 2015.

[32] J. Huang, P. Leandri, G. Cuciniello, and M. Losa, "Mix design and laboratory characterisation of rubberised mixture used as damping layer in pavements," International Journal of Pavement Engineering, pp. 1-15, 2021.

[33] J. Huang, G. S. Kumar, and Y. Sun, "Evaluation of workability and mechanical properties of asphalt binder and mixture modified with waste toner," Construction and Building $\mathrm{Ma}$ terials, vol. 276, Article ID 122230, 2021.

[34] J. Huang, M. Koopialipoor, and D. J. Armaghani, “A combination of fuzzy delphi method and hybrid ann-based systems to forecast ground vibration resulting from blasting," Scientific Reports, vol. 10, pp. 19397-19421, 2020.

[35] J. Huang, T. Duan, Y. Zhang, J. Liu, J. Zhang, and Y. Lei, "Predicting the permeability of pervious concrete based on the beetle antennae search algorithm and random forest model," Advances in Civil Engineering, vol. 2020, Article ID 8863181, 11 pages, 2020.

[36] J. Huang, T. Duan, Y. Sun, L. Wang, and Y. Lei, "Finite element ( $\mathrm{fe}$ ) modeling of indirect tension to cylindrical (it-cy) specimen test for damping asphalt mixtures (dams),"
Advances in Civil Engineering, vol. 2020, Article ID 6694180, 11 pages, 2020.

[37] J. Huang, T. Duan, Y. Lei, and M. Hasanipanah, "Finite element modeling for the antivibration pavement used to improve the slope stability of the open-pit mine," Shock and Vibration, vol. 2020, Article ID 6650780, 11 pages, 2020.

[38] J. Huang, G. Cuciniello, P. Leandri, and M. Losa, "Design of rubberized asphalt mixtures for noise and vibration damping layers," in Proceedings of the Advances in Materials and Pavement Performance Prediction II: Contributions to the 2nd International Conference on Advances in Materials and Pavement Performance Prediction (AM3P 2020), p. 269, CRC Press, San Antonio, TX, USA, May 2020.

[39] J. Huang, P. G. Asteris, S. M. K. Pasha, A. S. Mohammed, and M. Hasanipanah, "A new auto-tuning model for predicting the rock fragmentation: a cat swarm optimization algorithm," Engineering with Computers, Springer, Berlin, Germany, 2020.

[40] J. Huang, R. Alyousef, M. Suhatril et al., "Influence of porosity and cement grade on concrete mechanical properties," $\mathrm{Ad}$ vances in Concrete Construction, vol. 10, pp. 393-402, 2020.

[41] Y. Sun, G. Li, J. Zhang, J. Sun, and J. Xu, "Development of an ensemble intelligent model for assessing the strength of cemented paste backfill," Advances in Civil Engineering, vol. 2020, Article ID 1643529, 6 pages, 2020.

[42] Y. Sun, G. Li, H. Basarir, A. Karrech, and M. R. Azadi, "Laboratory evaluation of shear strength properties for cement-based grouted coal mass," Arabian Journal of Geosciences, vol. 12, no. 22, p. 690, 2019.

[43] M. S. Sumanasooriya and N. Neithalath, "Pore structure features of pervious concretes proportioned for desired porosities and their performance prediction," Cement and Concrete Composites, vol. 33, no. 8, pp. 778-787, 2011.

[44] A. Subhy, D. Lo Presti, and G. Airey, "An investigation on using pre-treated tyre rubber as a replacement of synthetic polymers for bitumen modification," Road Materials and Pavement Design, vol. 16, no. 1, pp. 245-264, 2015.

[45] D. Shi, P. W. Brown, and W. Ma, "Lognormal simulation of pore size distributions in cementitious materials," Journal of the American Ceramic Society, vol. 74, no. 8, pp. 1861-1867, 1991.

[46] M. Sheshpari, "A review of underground mine backfilling methods with emphasis on cemented paste backfill," Electronic Journal of Geotechnical Engineering, vol. 20, pp. 5183-5208, 2015.

[47] A. Shadravan, M. Tarrahi, and M. Amani, "Intelligent tool to design fracturing, drilling, spacer and cement slurry fluids using machine learning algorithms," in Proceedings of the SPE Kuwait Oil and Gas Show and Conference, Mishref, Kuwait, October 2015.

[48] A. Shadravan, M. Tarrahi, and M. Amani, "Intelligent cement design: utilizing machine learning algorithms to assure effective long-term well integrity," in Proceedings of the Carbon Management Technology Conference, Sugar Land, TX, USA, November 2015.

[49] J. Ren, S. Wang, and G. Zang, "Effects of recycled aggregate composition on the mechanical characteristics and material design of cement stabilized cold recycling mixtures using road milling materials," Construction and Building Materials, vol. 244, Article ID 118329, 2020.

[50] J. Zhang, Y. Wang, Y. Sun, and G. Li, "Strength of ensemble learning in multiclass classification of rockburst intensity," International Journal for Numerical and Analytical Methods in Geomechanics, vol. 44, no. 13, pp. 1833-1853, 2020. 
[51] J. Zhang, Y. Sun, G. Li, Y. Wang, J. Sun, and J. Li, "Machinelearning-assisted shear strength prediction of reinforced concrete beams with and without stirrups," Engineering with Computers, pp. 1-15, 2020.

[52] J. Zhang, D. Li, and Y. Wang, "Toward intelligent construction: prediction of mechanical properties of manufactured-sand concrete using tree-based models," Journal of Cleaner Production, vol. 258, Article ID 120665, 2020.

[53] J. Zhang, D. Li, and Y. Wang, "Predicting tunnel squeezing using a hybrid classifier ensemble with incomplete data," Bulletin of Engineering Geology and the Environment, vol. 79, pp. 1-12, 2020.

[54] J. Zhang, F. Jiang, S. Zhu, and L. Zhang, "Width design for gobs and isolated coal pillars based on overall burst-instability prevention in coal mines," Journal of Rock Mechanics and Geotechnical Engineering, vol. 8, no. 4, pp. 551-558, 2016.

[55] J. Zhang, Y. Huang, Y. Wang, and G. Ma, "Multi-objective optimization of concrete mixture proportions using machine learning and Metaheuristic algorithms," Construction and Building Materials, vol. 253, Article ID 119208, 2020.

[56] J. Zhang, Y. Huang, G. Ma, J. Sun, and B. Nener, “A metaheuristic-optimized multi-output model for predicting multiple properties of pervious concrete," Construction and Building Materials, vol. 249, Article ID 118803, 2020.

[57] J. Zhang, Y. Huang, F. Aslani, G. Ma, and B. Nener, "A hybrid intelligent system for designing optimal proportions of recycled aggregate concrete," Journal of Cleaner Production, vol. 273, Article ID 122922, 2020.

[58] J. Huang, Y. Zhang, Y. Sun, J. Ren, Z. Zhao, and J. Zhang, "Evaluation of pore size distribution and permeability reduction behavior in pervious concrete," Construction and Building Materials, vol. 290, Article ID 123228, 2021.

[59] J. Huang, J. Zhang, J. Ren, and H. Chen, “Anti-rutting performance of the damping asphalt mixtures (dams) made with a high content of asphalt rubber (ar)," Construction and Building Materials, vol. 271, Article ID 121878, 2021.

[60] J. Huang, Y. Sun, and J. Zhang, "Reduction of computational error by optimizing svr kernel coefficients to simulate concrete compressive strength through the use of a human learning optimization algorithm," Engineering with Computers, Springer, Berlin, Germany, 2021.

[61] J. Huang and Y. Sun, "Viscoelastic analysis of the damping asphalt mixtures (dams) made with a high content of asphalt rubber (ar)," Advances in Civil Engineering, vol. 2020, Article ID 8826926, 12 pages, 2020.

[62] J. Huang and Y. Sun, "Effect of modifiers on the rutting, moisture-induced damage, and workability properties of hot mix asphalt mixtures," Applied Sciences, vol. 10, no. 20, p. $7145,2020$.

[63] J. Huang, G. Shiva Kumar, J. Ren, J. Zhang, and Y. Sun, "Accurately predicting dynamic modulus of asphalt mixtures in low-temperature regions using hybrid artificial intelligence model," Construction and Building Materials, vol. 297, Article ID 123655, 2021.

[64] J. Huang, G. Shiva Kumar, J. Ren, Y. Sun, Y. Li, and C. Wang, "Towards the potential usage of eggshell powder as biomodifier for asphalt binder and mixture: workability and mechanical properties," International Journal of Pavement Engineering, pp. 1-13, 2021.

[65] J. Huang, M. Losa, P. Leandri, S. G. Kumar, J. Zhang, and Y. Sun, "Potential anti-vibration pavements with damping layer: finite element (fe) modeling, validation, and parametrical studies," Construction and Building Materials, vol. 281, Article ID 122550, 2021.
[66] J. Huang, M. Losa, and P. Leandri, "Determining the effect of damping layers in flexible pavements on traffic induced vibrations," in Proceedings of the Advances in Materials and Pavement Prediction: Papers from the International Conference on Advances in Materials and Pavement Performance Prediction (AM3P 2018), pp. 255-259, CRC Press, Doha, Qatar, April 2018.

[67] Y. Sun, G. Li, J. Zhang, and J. Xu, "Failure mechanisms of rheological coal roadway," Sustainability, vol. 12, no. 7, p. 2885, 2020.

[68] Y. Sun, G. Li, J. Zhang, and D. Qian, "Experimental and numerical investigation on a novel support system for controlling roadway deformation in underground coal mines," Energy Science \& Engineering, vol. 8, no. 2, pp. 490-500, 2020.

[69] Y. Sun, G. Li, J. Zhang, and D. Qian, "Prediction of the strength of rubberized concrete by an evolved random forest model," Advances in Civil Engineering, vol. 2019, Article ID 5198583, 7 pages, 2019.

[70] Y. Sun, G. Li, J. Zhang, and D. Qian, "Stability control for the rheological roadway by a novel high-efficiency jet grouting technique in deep underground coal mines," Sustainability, vol. 11, no. 22, p. 6494, 2019.

[71] Y. Sun, G. Li, and J. Zhang, "Developing hybrid machine learning models for estimating the unconfined compressive strength of jet grouting composite: a comparative study," Applied Sciences, vol. 10, no. 5, p. 1612, 2020.

[72] Y. Sun, G. Li, and J. Zhang, "Investigation on jet grouting support strategy for controlling time-dependent deformation in the roadway," Energy Science \& Engineering, vol. 8, 2020.

[73] F. Khademi, S. M. Jamal, N. Deshpande, and S. Londhe, "Predicting strength of recycled aggregate concrete using artificial neural network, adaptive neuro-fuzzy inference system and multiple linear regression," International Journal of Sustainable Built Environment, vol. 5, no. 2, pp. 355-369, 2016.

[74] F. Khademi and S. M. Jamal, "Estimating the compressive strength of concrete using multiple linear regression and adaptive neuro-fuzzy inference system," International Journal of Structural Engineering, vol. 8, no. 1, pp. 20-31, 2017.

[75] K. Cheng and Z. Lu, "Adaptive bayesian support vector regression model for structural reliability analysis," Reliability Engineering \& System Safety, vol. 206, Article ID 107286, 2021.

[76] E. S. Chahnasir, Y. Zandi, M. Shariati et al., "Application of support vector machine with firefly algorithm for investigation of the factors affecting the shear strength of angle shear connectors," Smart Structures and Systems, vol. 22, pp. 413-424, 2018.

[77] J. Bi and K. P. Bennett, "A geometric approach to support vector regression," Neurocomputing, vol. 55, no. 1-2, pp. 79-108, 2003.

[78] N. Hasan, N. C. Nath, and R. I. Rasel, "A support vector regression model for forecasting rainfall," in 2015 2nd International Conference on Electrical Information and Communication Technologies (EICT), pp. 554-559, IEEE, Khulna, Bangladesh, December 2015.

[79] H. Drucker, C. J. Burges, L. Kaufman, A. Smola, and V. Vapnik, "Support vector regression machines," Advances in Neural Information Processing Systems, vol. 9, pp. 155-161, 1997.

[80] W.-C. Hong and G.-F. Fan, "Hybrid empirical mode decomposition with support vector regression model for short term load forecasting," Energies, vol. 12, no. 6, p. 1093, 2019.

[81] M. Hasanipanah, M. Monjezi, A. Shahnazar, D. Jahed Armaghani, and A. Farazmand, "Feasibility of indirect determination of blast induced ground vibration based on support vector machine," Measurement, vol. 75, pp. 289-297, 2015. 